\title{
Combined eye gel containing sodium hyaluronate and xanthan gum for the treatment of the corneal epithelial defect after pterygium surgery
}

This article was published in the following Dove Press journal:

Clinical Ophthalmology

13 August 2015

Number of times this article has been viewed

\author{
Tolga Kocatürk' \\ Ataman Gençgönül ${ }^{2}$ \\ Faruk Balica' \\ Mehmet Özbağcivan' \\ Harun Çakmak' \\ 'Department of Ophthalmology, \\ Faculty of Medicine, Adnan Menderes \\ University, Aydın, ${ }^{2}$ Department \\ of Ophthalmology, Mevki Military \\ Hospital, Ankara, Turkey
}

Aim: The aim of this study is to compare the effectiveness of the ophthalmic gels containing hyaluronate, xanthan gum, and netilmycine with fusidic acid in terms of recovery periods of corneal epithelium in the patients who underwent pterygium surgery.

Methods: Patients who underwent pterygium surgery were separated into two groups. Forty patients in group 1 were given eye gel containing sodium hyaluronate, xanthan gum, and netilmycine, and 40 patients in group 2 were given one drop of eye gel containing fusidic acid. The patients in both groups were examined at the 12th, 24th, and 48th hours in the postoperative period by using slit-lamp technique. The subjective complaints of the patients such as pain and stinging, and the recovery periods of the corneal epithelial defect were evaluated comparatively by fluorescein staining.

Results: The mean ages were $26 \pm 8$ years (range: $18-35$ ) and $24 \pm 6$ years (range: $18-33$ ) in groups 1 and 2, respectively. The closure period of the corneal epithelial defect was observed as $24 \pm 8$ hours (range: $16-42$ ) and $36 \pm 12$ hours (range: 18-48) in groups 1 and 2 , respectively. The number of the patients suffering from subjective complaints such as pain and stinging in the first 12 hours was six and 29 in groups 1 and 2, respectively. The difference was significant both clinically and statistically $(P=0.001)$.

Conclusion: Combined eye gel containing hyaluronate, xanthan gum, and netilmycine accelerates the recovery of corneal epithelial defect and reduces the complaints of the patients, when compared to the fusidic acid gel. Combined eye gel should be considered as an option for the treatment of the corneal epithelial defect related with pterygium surgery.

Keywords: iatrogenic corneal epithelial defect, netilmycine, fusidic acid, ophthalmic gel

\section{Introduction}

Corneal epithelial defect that might be seen as dependent on various reasons in the daily ophthalmology practice is a situation characterized by irritating symptoms such as pain, stinging, foreign body sensation, and photophobia and may cause loss of eye sight. It not only affects the quality of life of a person, but also causes loss of labor. Uncomplicated and minor ones spontaneously heal in a few days. In major defects, use of eye closure treatment, antibiotics, cycloplegic eye drops, and analgesics are recommended.

Corneal epithelial defect often occurs iatrogenic after the pterygium surgery. Reducing the complaints of the patient in the postoperative period after the surgery and getting the cornea epithelialized swiftly and in a healthy way are the objectives of this study.

The aim of this study is to compare the combined eye gel (Xanternet; SIFI SpA, Catania, Italy) containing sodium hyaluronate $0.15 \%$ and xanthan gum $1 \%$ in addition to netilmycine $0.3 \%$ used to close the eye after pterygium surgery and viscose eye gel
Correspondence: Tolga Kocatürk Adnan Menderes Üniversitesi Tıp Fakültesi Uygulama ve Araștırma Hastanesi, Göz Hastalıkları AD, 09100, Aydın, Turkey Tel +90533344 4l I I Email tolgakocaturk@gmail.com 
(Fucithalmic $^{\circledR}$; Leo Pharma Ballerup, Denmark) containing fusidic acid $1 \%$ in terms of recovery periods of corneal epithelium and the complaints of the patient. We also targeted to research the effectiveness of the ophthalmic solution containing hyaluronate, xanthan gum, and netilmycine as an alternative way of treatment, in addition to the medication used in such a period.

\section{Methods}

The patients who underwent pterygium surgery in Adnan Menderes University Hospital, Aydın, Turkey and Mevki Military Hospital, Ankara, Turkey were included in this study. This study was approved by the ethics committee of Adnan Menderes University Hospital, Aydın, Turkey and was conducted in accordance with the guidelines of the Declaration of Helsinki.

Patients with iatrogenic corneal epithelial defects were randomly divided into two groups during the pterygium surgery and were treated as follows after the surgery. Patients were randomly added to groups and did not know which therapy has been given to them. Informed consent was taken from all patients. Detailed medical history of patients was recorded, and full ophthalmological examination including fluorescein staining was performed before and after the surgery procedure. All of the surgeries were performed in operation room in a standard fashion. After the application of topical anesthesia with $0.5 \%$ proparacaine (Alcaine, proparacaine hydrochloride ophthalmic solution, USP), 5\% povidone-iodine was dropped. Eyelids and periorbital tissues were cleaned by $10 \%$ povidone-iodine. After injection of jetocaine into pterygium tissue, by blunt dissection, the tissue was separated from corneal remnants of pterygium tissue extirpated by bevel-up knife. After the excision of pterygium tissue, conjunctival graft from superotemporal bulbar conjunctiva was slid over bare area. Graft was sutured to conjunctiva by 7-0 vicryl suture. After applying eye gel, eye was closed by roundel. Patients who iatrogenically had epithelial defects were randomly added into two groups. Forty patients in group 1 were given eye gel containing $0.15 \%$ sodium hyaluronate, $1 \%$ xanthan gum, and $0.3 \%$ netilmycine (Xanternet; SIFI SpA), and 40 patients in group 2 were given one drop of eye gel containing $1 \%$ fusidic acid (Fucithalmic ${ }^{\circledR}$; Leo Pharma). After the eye gels were dropped, pressure dressing was applied to the patients in both groups for 12 hours, and the patients were monitored for 48 hours. The patients in both groups were examined at the 12th, 24th, and 48th hours in the postoperative period. Besides, the recovery periods of the corneal epithelial defect and the subjective complaints of the patients such as pain and stinging were also evaluated; corneal epithelial defects were stained with fluorescein strips (Visimed Fluo Test Çubuk; Visimed Ltd, Izmir, Turkey) and examined by using slit-lamp under cobalt blue filter. The patients with additional ocular diseases and those with insufficient data were excluded from the study. The epithelial defects of the patients were controlled by using fluorescein staining during postoperative examination. After both the gels were applied, the eyes were closed by roundel until the epithelial defects recovered, and no additional medication was given during this period. The patients who did not take the treatment regularly as well as those, who could not attend the controls were excluded from the study.

\section{Statistical analysis}

Mean values of both groups were calculated using Statistical Package for the Social Sciences ${ }^{\mathrm{TM}} 20.0$ (SPSS Inc., Chicago, IL, USA) software. Results were reported as the mean \pm standard deviation, frequency, and percentage. Independent samples $t$-test was used to evaluate the significance of the differences between the groups. Any $P$-value below 0.05 was considered as statistically significant.

\section{Results}

The groups were similar according to demographic findings (Table 1). The mean ages in years were 26 \pm 8 (range:18-35) and 24 \pm 6 (range:18-33) in groups 1 and 2, respectively. There were 32 males (80\%) and eight females (20\%) in group 1; there were 28 males (70\%) and 12 females (30\%) in group 2 . Corneal epithelial defect was evaluated by fluorescein staining, and the closure period of the corneal epithelial defect was observed as $24 \pm 8$ (range: $16-42$ ) and 36 \pm 12 (range: $18-48$ ) hours in groups 1 and 2 , respectively. The number of the patients suffering from subjective complaints such as pain and stinging in the first 12 hours was six and 29 in groups 1 and 2, respectively. The difference was significant both clinically and statistically $(P=0.001)$. None of the patients included in the study suffered from infection, systemic or local side effects of medications, or any other complications. Three patients who did not attend the follow-ups were excluded from the study.

Table I Comparison of the groups according to age, sex, and healing period

\begin{tabular}{llll}
\hline & Group I & Group 2 & P-value \\
\hline Age (years) & $26 \pm 8$ (range: I8-35) & $24 \pm 6$ (range: I8-33) & $0.7 \mid 4$ \\
Female/male & $8 / 32(20 \% / 80 \%)$ & $12 / 28(30 \% / 70 \%)$ & 0.642 \\
$\begin{array}{l}\text { Epithelial healing } \\
\text { period (hours) }\end{array}$ & $24 \pm 8$ (range: 16-42) & $36 \pm 12$ (range: 18-48) & 0.001 \\
\hline
\end{tabular}




\section{Discussion}

Pterygium is an elevated growth of the bulbar conjunctiva bypassing the limbus borders and extending on the cornea surface. Histologically, it is accompanied by fibrovascular proliferation and inflammation. ${ }^{1,2}$ The treatment is surgical excision. Corneal abrasion is a traumatic defect formed iatrogenic during the pterygium surgery. The corneal epithelial defect in almost all patients after the surgical procedure causes ocular symptoms such as pain and irritation that impairs the quality of life.

The corneal abrasion seldom turns to be complicated and often completely recovers in 24-48 hours depending on the way of treatment. ${ }^{3}$ Generally, a big epithelial defect that requires closure occurs after the pterygium surgery. The cornea is targeted to epithelialize without being infected and reducing the symptoms of the patient by the given treatments during the postoperative period such as closure, use of contact lenses, antibiotics, and artificial tears.

Closure of the eye in the treatment of corneal abrasion is still being discussed. It is thought that closure decreases the corneal oxygenation and increases the heat on the eye surface, and thus, increases the infection risk. ${ }^{4}$ In their study, Turner et $\mathrm{al}^{5}$ do not recommend closure for the defects smaller than $10 \mathrm{~mm}^{2}$. Binocular sight is also affected by closure. Soft contact lenses offer a better alternative for getting rid of some negations caused by closure, especially for the wide defects. However, contact lenses have their own negative sides such as infection, high cost, and requirement of frequent monitoring. Lubrication used in the treatment of corneal abrasion is also very important. Hydration and lubrication prevent friction by decreasing the surface disorder and compliment to the recovery of the corneal epithelial defect. Sodium hyaluronate and xanthan gum are polysaccharides with high molecular weight, and they help protect the cornea by retaining liquid and ensuring hydration. ${ }^{6,7}$ The performed studies proved that sodium hyaluronate helps treatment by increasing cell migration for the recovery of the corneal epithelial defect. ${ }^{8}$ Netilmycine is a third-generation aminoglycoside, and because it is not cytotoxic, it does not adversely affect the recovery of the wound. Therefore, it can be used safely for this process. ${ }^{9}$ Because the combined eye gel does not include a preservative substance, this is accepted as a positive feature for the recovery of the wound. In their study, Faraldi et al proved that use of hyaluronate acid and xanthan gum in addition to netilmycine for the treatment of the traumatic corneal abrasion shortened the closure time. ${ }^{10}$

One of the limitations in this study is the absence of pre- and postoperative visual acuity comparison. We have studied the first 48 hours of postoperative period of the patients. It would be misleading to speak of visual acuity in this period. Mean age of patients was relatively less, because this study was performed in a military hospital, so our results reflect this young age group. Similar studies including different ages may add beneficial results to literature. Further studies are needed with older population. In our clinic, fusidic acid is one of the most preferable eye gels, so we compared this new medication with fusidic acid. Some different eye gel comparisons can also be made in a similar manner.

In this study, we studied the effects of the combined eye gel containing hyaluronate and xanthan gum together with netilmycine as well as the fusidic acid, used very often in practice, on the recovery period of the corneal epithelial defect. As can be seen from the results, the combined eye gel accelerates the recovery of the wound, when compared to the fusidic acid, and the complaints of the patients reduce. We may come to the conclusion that it is an effective medication for the treatment of the epithelial defect related with pterygium surgery due to the polysaccharides it contains, along with the antibiotics. When we consider that almost all of the patients suffer from epithelial defect after the pterygium surgery, which is often performed in practice of ophthalmology, choice of medication that will help the swift and safe closure of the epithelial defects as well as reduce the complaints of the patients is of paramount importance. It has been found out that short closure treatment period (12 hours) is adequate for the patients who had pterygium surgery. It has also been found out as a result of this study that it is suitable to use Xanternet $2 \times 1$ as a treatment alternative for this patient group in the postoperative period. Thus, we think, sufficient and effective treatment will be ensured by using only one ophthalmic solution during the postoperative period, and fewer problems will be experienced regarding the patient compliance. Comparison of this treatment method with different patient groups and other postoperative treatment regimens may be beneficial for the assessment of its effectiveness.

\section{Disclosure}

The authors report no conflicts of interest in this work.

\section{References}

1. Hill JC, Maske R. Pathogenesis of pterygium. Eye (Lond). 1989;3(pt 2) 218-226.

2. Cameron ME. Histology of pterygium. An electron microscopic study. Br J Ophthalmol. 1983;67(9):604-608.

3. Wilson SA, Last A. Management of corneal abrasions. Am Fam Physician 2004;70:123-128

4. Flynn CA, D'Amico F, Smith G. Should we patch corneal abrasions? A meta-analysis. J Fam Pract. 1998;47(4):264-270. 
5. Turner A, Robiu M. Patching for corneal abrasions. Cochrane Database Syst Rev. 2006;19(2):CD004764.

6. Goa KL, Benfield P. Hyaluronic acid A review of its pharmacology and use as a surgical aid in ophthalmology and its therapeutic potential in joint disease and wound healing. Drugs. 1994;47(3):536-566.

7. Ceulemas J, Vinckier I, Ludwig A. The use of xanthan gum in an ophthalmologic liquid dosage form: rheologicalchracterization of the interaction with mucin. J Pharm Sci. 2002;91(4):1117-1127.
8. Nishida T, Nakamura M, Mishima H. Hyaluronan stimulates corneal epithelial migration. Exp Eye Res. 1991;53(6):753-758.

9. Scuderi AC, Paladino GM. In vitro toxicity of netilmicin and ofloxacin on corneal epithelial cells. Cornea. 2003;22(5):468-472.

10. Faraldi F, Papa V. A new eye gel containing sodium hyaluronate and xanthan gum for the management of post-traumatic corneal abrasions. Clin Ophthalmol. 2012;6:727-731.

\section{Publish your work in this journal}

Clinical Ophthalmology is an international, peer-reviewed journal covering all subspecialties within ophthalmology. Key topics include: Optometry; Visual science; Pharmacology and drug therapy in eye diseases; Basic Sciences; Primary and Secondary eye care; Patient Safety and Quality of Care Improvements. This journal is indexed on

\section{Dovepress}

PubMed Central and CAS, and is the official journal of The Society of Clinical Ophthalmology (SCO). The manuscript management system is completely online and includes a very quick and fair peer-review system, which is all easy to use. Visit http://www.dovepress.com/ testimonials.php to read real quotes from published authors. 